\title{
INTRODUCTION
}

\section{Seabirds and climate change: roadmap for the future}

\author{
William J. Sydeman ${ }^{1, *}$, Sarah Ann Thompson ${ }^{1}$, Alexander Kitaysky ${ }^{2}$ \\ ${ }^{1}$ Farallon Institute for Advanced Ecosystem Research, Petaluma, California 94952, USA \\ ${ }^{2}$ Institute of Arctic Biology, Department of Biology and Wildlife, University of Alaska Fairbanks, Fairbanks, Alaska 99775, USA
}

\begin{abstract}
Based in part on a symposium held at the first World Seabird Conference in September, 2010 in Victoria, BC, Canada, we present a Theme Section (TS) on the topic of seabirds and climate change. We introduce this TS with a meta-analysis of key attributes of the current seabird-climate literature, based on 108 publications representing almost 3000 seabird-climate associations (mostly correlations) published up to 2011. Using the papers in this TS and our metaanalysis, a brief roadmap for the future of seabird-climate change research is presented. Seabird studies have contributed substantially to the literature on marine climate effects. To improve our understanding of climate change effects on seabirds at the global scale, however, additional lowlatitude, mechanistic, and 'end-to-end' modeling studies, including integration of climatic, oceanographic, food web, and population dynamics models, should be conducted. This approach will enhance our understanding of the relationship between climate and population dynamics, and facilitate seabird conservation in a changing world.
\end{abstract}

KEY WORDS: Conference proceedings $\cdot$ Climate effects $\cdot$ Marine birds $\cdot$ Meta-analysis

\section{INTRODUCTION}

It is now widely accepted that climate variability and change have strong, persistent effects on marine ecosystems (Stenseth et al. 2002, Harley et al. 2006, Hoegh-Guldberg \& Bruno 2010). The Intergovernmental Panel on Climate Change (IPCC) projects mean increases in air temperature of $1.1^{\circ} \mathrm{C}$ by the $2020 \mathrm{~s}, 1.8^{\circ} \mathrm{C}$ by the $2040 \mathrm{~s}$, and $3.0^{\circ} \mathrm{C}$ by the $2080 \mathrm{~s}$ as a result of rising greenhouse gas concentrations (Solomon et al. 2007). Much of this heat will be absorbed by the world's oceans. Already, as a result of past changes in air temperature, heat content of the ocean has increased dramatically (Belkin 2009, Levitus et al. 2009, Burrows et al. 2011). Given ocean warming, coupled with other predicted physical changes including sea level rise and declines in sea ice, effects on marine life are expected to intensify in the coming century. Consequently, the need to improve our understanding of the effects of climate change on various marine organisms has become urgent to facilitate effective species and ecosystem conservation as well as protection of the various ecosystem services that marine environments provide for society (Richardson \& Poloczanska 2008, Doney et al. 2012).

Seabirds exist at the ecotone of the atmosphere and the ocean, use both marine and terrestrial habitats, and therefore may be particularly sensitive to multiple and potentially synergistic climate variations. It has been suggested that seabirds are reliable indicators of ecosystem change associated with climatic as well as other anthropogenic and natural factors (Cairns 1987, MEPS 2007, 2009, reviewed by Durant et al. 2009). Seabirds are the most threatened marine taxonomic group in the world, with $\sim 25 \%$ of species currently listed as threatened or considered of special concern (IUCN 2011, Croxall et al. 2012). In addi- 
tion to climate change, threats to seabird populations include habitat loss and degradation due to invasive species, coastal development, physiological stressors due to food shortages and pollution, and mortality due to by-catch in certain types of fishing (i.e. Lewison et al. 2012). In relation to climatic factors, effects on seabirds appear to be mostly indirect, operating through changes in local to regional food webs and the pelagic habitat. Seabirds mainly rely on micronekton (forage fish and squids) and mesozooplankton (copepods and krill) for successful foraging. Owing to their lower trophic positioning, micronekton and particularly mesozooplankton are likely more sensitive to climatic variations than upper trophic level species such as seabirds (Richardson 2008). However, changes in the distribution and abundance of prey would have direct effects on seabirds through changes in bottom-up food web dynamics (Ware \& Thomson 2005) and predatorprey interactions. At breeding colonies, seabirds could be affected by warming of air temperature and in some cases changes in the timing or intensity of precipitation, which may inhibit access to nesting colonies or, in severe cases, cause mortality due to overheating and physiological stress. How different seabird species will respond to coupled climate and ecosystem change is undoubtedly related to many factors, including life history characteristics, food habits, range, and abundance (e.g. Furness \& Tasker 2000). Furthermore, some seabirds may fare well in a warming ocean, whereas others may become locally, regionally, or perhaps even globally extinct (e.g. Kitaysky \& Golubova 2000, Jenouvrier et al. 2009, Wolf et al. 2010, Lewison et al. 2012). Fortunately, many demographically comprehensive, long-term studies of seabirds (e.g. Barbraud \& Weimerskirch 2001) provide a rich information base for assessments of ongoing and future climatic effects on seabird populations, species, and communities. These studies often include information on food habits, seasonality, and species interactions, so that mechanisms of demographic or distributional change may be properly inferred (Cury et al. 2011).

In anticipation of the next IPCC report, Assessment Report 5, currently scheduled for release in 2014, the purpose of this Theme Section (TS) is to provide a series of up-to-date studies which investigate and evaluate how climate variability and change have affected and may affect seabirds in the future. This TS is based mainly on a symposium held in conjunction with the first World Seabird Conference (WSC) from 7 to 11 September 2010 in Victoria, British Columbia, Canada. The WSC was hosted by the
Pacific Seabird Group (PSG) in cooperation with almost 2 dozen other organizations and societies from across the globe (www.worldseabirdconference.com/main.cfm?cid=1813). The papers in this TS investigated how climate variability and change might affect phenology (timing of breeding, migration), breeding or roosting habitat, range, demographic traits (breeding success, survival, recruitment), at-sea distribution, nutritional stress, food habits (diet composition), and community structure of seabirds, covering 10 ecosystems from both the northern and southern hemispheres (Table 1). These variables have been identified as key response types from previous ecological investigations (Sydeman et al. 2009, Weimerskirch et al. 2012). From the onset, we solicited studies that provided quantitative links between trends in the physical environment variables hypothesized to be affected by climate change (i.e. water temperature and stratification, winds and currents, sea level, ocean acidification, and $\mathrm{pH}$ ), and trends in seabird parameters (see Brown et al. 2011). Most papers in this TS met this goal.

\section{ROADMAP TO THE FUTURE}

\section{Meta-analysis}

To place the papers of this TS in perspective, we conducted a literature review and provide an initial meta-analysis (cf. Parmesan \& Yohe 2003, Rosenzweig et al. 2008) of data gleaned from 108 seabirdclimate studies published in primary journals (see the Supplement at www.int-res.com/articles/suppl/m454 p107_supp.pdf). We conducted this literature review using the ISI Web of Knowledge based on the following search terms: (1) seabirds climate change, (2) seabirds climate variability, (3) seabird climate trends, (4) seabird climate food availability, (5) seabird climate variation, and (6) seabirds climate. We mined the literature cited sections of prominent authors to find more papers about seabirds and climate change. Inclusion requirements were that each study had to be longer than $2 \mathrm{yr}$ in duration, and authors had to state explicitly that one of their objectives was to explore the effects of climatic factors on a seabird-dependent variable. From these 108 papers, a total of 2877 records of seabird-climate associations (mostly correlations and regression results) were compiled, irrespective of reported statistical significance (though significance was noted). A record is defined as a statistical test between a seabird response (dependent) variable against a climate 


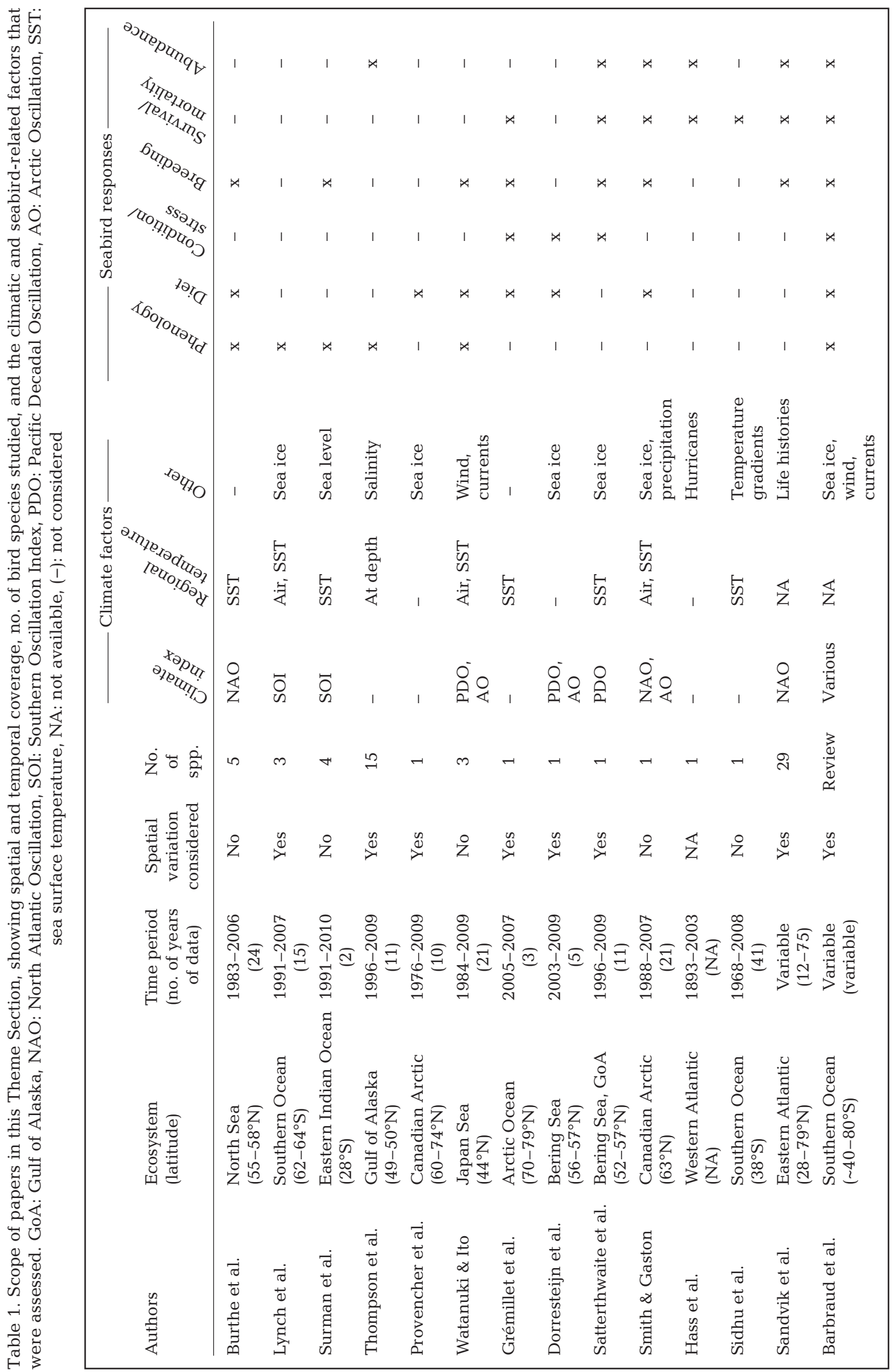


(independent) variable. On average, we tabulated $\sim 27$ tests per paper, and found that few authors adjusted for multiple tests in their analyses, nor did many authors test or adjust for autocorrelation in climatic or seabird time series. Our search and initial meta-analysis of the seabird-climate literature should not be considered comprehensive; new papers published after 2011 are not included, and literature from certain key regions (e.g. Southern Ocean) is somewhat incomplete due to limitations in our search criteria. However, our review and analysis can be considered representative of the literature on seabird-climate interactions up to 2011. As such, it provides a benchmark with which to evaluate the papers published in this TS as well as a key part of defining a roadmap for the future of seabird-climate research.

\section{Climate variability versus climate change}

We summarized previous studies with respect to the author's objectives and found that $49 \%$ of the papers were focused on 'climate variability' whereas $28 \%$ emphasized 'climate change', and $23 \%$ referred to both climate change and climate variability as objectives. These statistics suggest that about half of the previous studies were intended as studies of climate change effects on seabirds. Note that in this TS, all of the papers were intended to be about climate change, though in some cases, authors explored climate variability as a means to explore potential climate change effects in the future.

\section{Global coverage}

With respect to climatic effects, seabirds are a wellknown taxonomic group, with study sites distributed around the world (Fig. 1A). Previous studies of seabird-climate interactions are concentrated in the NE Atlantic (North Sea, Norwegian Sea) and off the west coast of North America (California Current to Gulf of Alaska). While studies are widely distributed, there are many regional oceans with little or no information. There are few studies in the large oligotrophic or equatorial upwelling regions of the central Atlantic and Pacific Oceans. In the sub-tropical central Indian Ocean, however, there have been several seabird-climate studies. A summary of latitudinal variation in study location demonstrates that tropical and sub-tropical regions, in particular, are under-represented in the seabird-climate literature
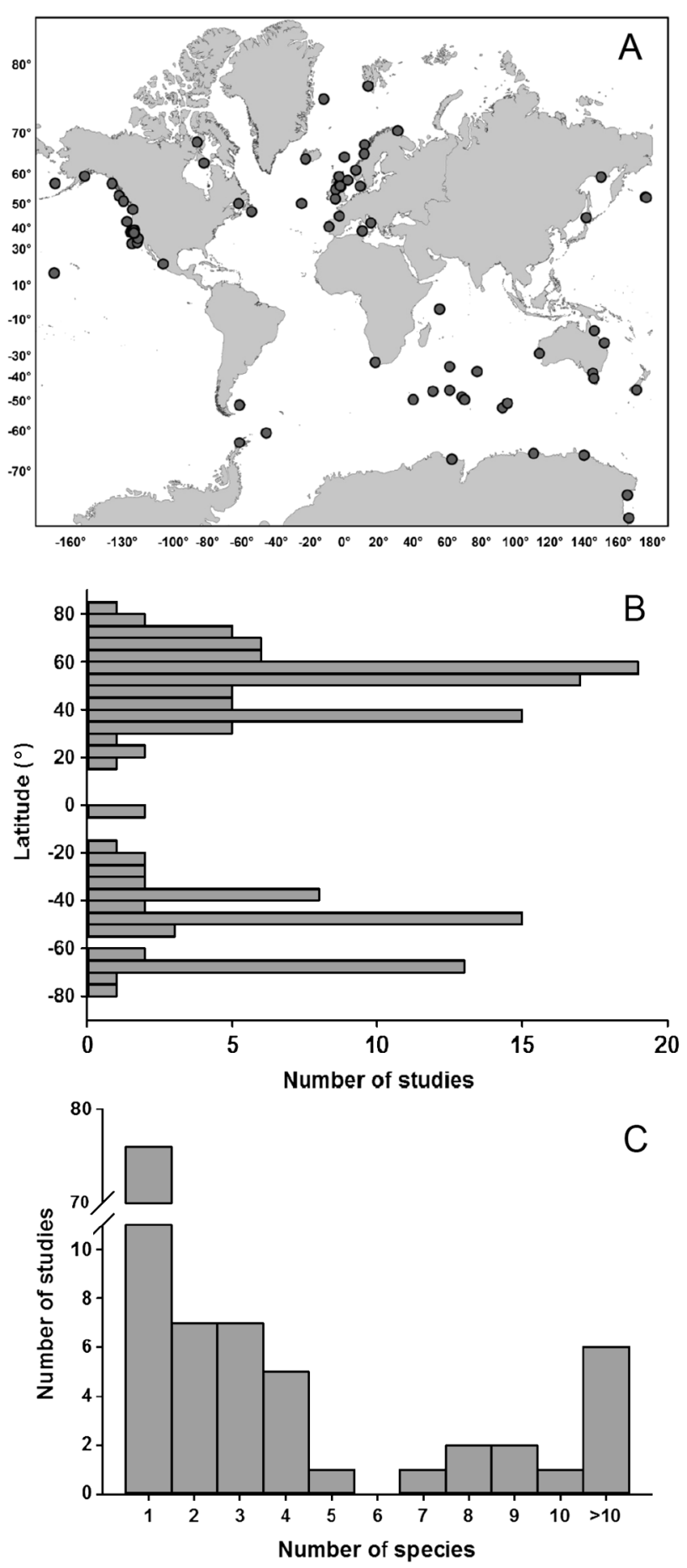

Fig. 1. (A) Study locations, (B) latitudinal distribution and (C) number of species per study in 108 publications on seabirds and climate change

(Fig. 1B). Some of the contributions to this TS help to fill some of these gaps in the global coverage of seabird-climate investigations, e.g. for the sub-arctic Bering Sea (Dorresteijn et al. 2012, Satterthwaite et al. 2012), the sub-tropical western Atlantic (Hass et 
al. 2012), and the sub-tropical eastern Indian Ocean (Surman et al. 2012). More studies in various regions of the world are clearly needed for a global assessment of climate change on seabirds. To that end, some time series of seabird parameters in lowlatitude systems have been developed, but have not been analyzed in relation to climate (e.g. Young et al. 2012); we encourage researchers to use or share these data so that key questions pertaining to the effects of climatic factors on seabirds can be addressed for under-studied regions of the world.

\section{Number of species per study}

In our review of the literature, we found data on a total of 98 species with an average of 3 species per study, but most studies $(53.7 \%)$ were conducted on single species at single sites (Fig. 1C). A concern with using single-species studies in meta-analyses is that they may be publication biased, as only data sets demonstrating change might be deemed suitable for publication by journal reviewers and editors. While clearly important for syntheses of climate change effects on seabirds and other taxa, negative (no change) data could be difficult to publish unless combined with positive (change) data for other species. Notably, in previous global-scale meta-analyses on the biological effects of climate change, Parmesan \& Yohe (2003) and Parmesan (2007) only used multispecies studies. For a global synthesis of seabird-climate interactions, the number of species per study is a constraint. In this TS, only 2 of 12 original data papers (Sidhu et al. 2012, Smith \& Gaston 2012) are based on a single species studied at a single location (Table 1). About half of the papers presented here are based on multiple species, for which both positive 'change' and negative 'no change' results are reported. The other papers, which focus on single species, all include multiple study sites that allow for tests of spatial variability. The addition of spatial components (e.g. multiple colonies in a meta-population context) greatly enhances the information content (and degrees of freedom) of seabird responses and climatic factors, strengthening inferences regarding detection of change and attribution of observed variability to climatic factors.

\section{Temporal characteristics of previous studies}

Somewhat remarkably, $85 \%$ of seabird-climate studies reported on continuous (i.e. annual) seabird time series data sets. A total of $10 \%$ of previous studies reported on time series which were irregular (i.e. missing some years in an otherwise regular research program) and $4 \%$ compared seabird parameters in 2 different time periods. The mean period covered in the 108 papers was $\sim 23 \mathrm{yr}$, with an average of $\sim 20$ years of data per study. In this TS, the longest study covers $41 \mathrm{yr}$ (Sidhu et al. 2012). Statistically speaking, long-term, preferably continuous, studies are required to both detect and attribute change in taxa to climate change. Most methods of robust attribution, including multi-step meta-analysis (e.g. Rosenzweig et al. 2008, Hegerl et al. 2009), are based on multi-decadal time series which facilitate detection of change using statistical trend analyses, as well as integration of physical environmental and biological data that can be used to attribute change to natural and anthropogenic climate signals.

\section{Seabird parameters studied}

In previous studies, approximately $88 \%$ of the seabird-climate associations involved any of 5 seabird response (dependent) variables: reproduction (e.g. breeding success and other measures of reproductive performance), abundance, survival (of both adults and juveniles), phenology (timing measurements), and adult condition (Fig. 2A). Other measurements, which were more rarely investigated, included chick growth, community change, behavior, and distribution. Notably, distributional change is a key variable often reported for studies of climate change effects on plankton and fish (e.g. Beaugrand et al. 2002, Perry et al. 2005), yet distribution has not been a focus in previous seabird-climate research. In this TS, 8 papers considered change in reproduction, 6 investigated aspects of abundance, 7 considered survival/mortality parameters, 6 involved phenological measurements, 7 considered food habits, 2 included data on body condition, and 2 focused on nutritional stress (Table 1). Thus, we present a balanced set of seabird parameters, and notably a higher percentage than is typical in the literature on diet, a variable that provides direct linkages between changes in the physical and biological environments and seabird populations. However, as found in our meta-analysis, studies of seabird distribution and range shifts in relation to climate change were under-emphasized. Thompson et al. (2012b), however, report on a related topic, namely seasonal variation in distribution and abundance of seabirds in the southeast Gulf of Alaska. 

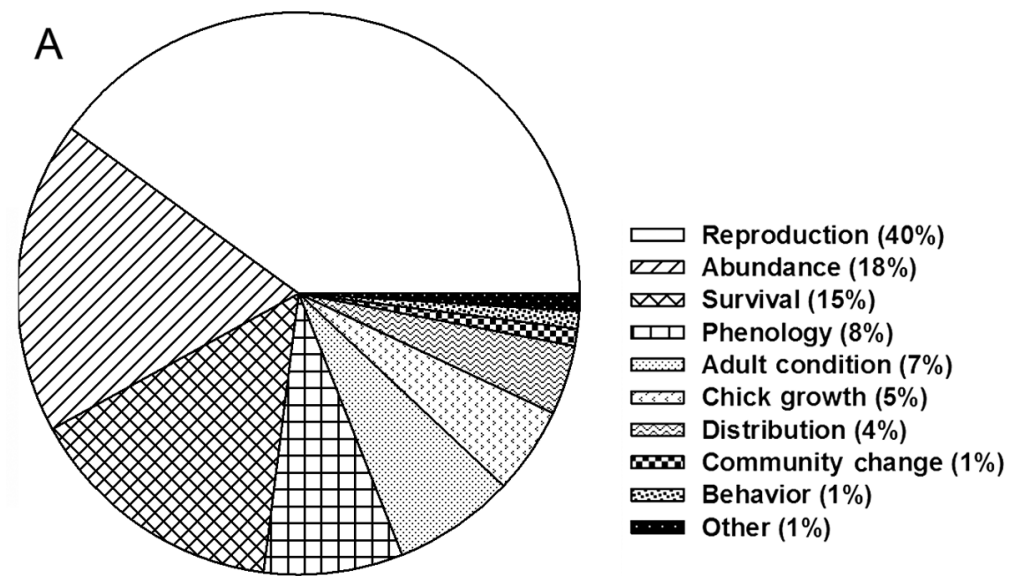
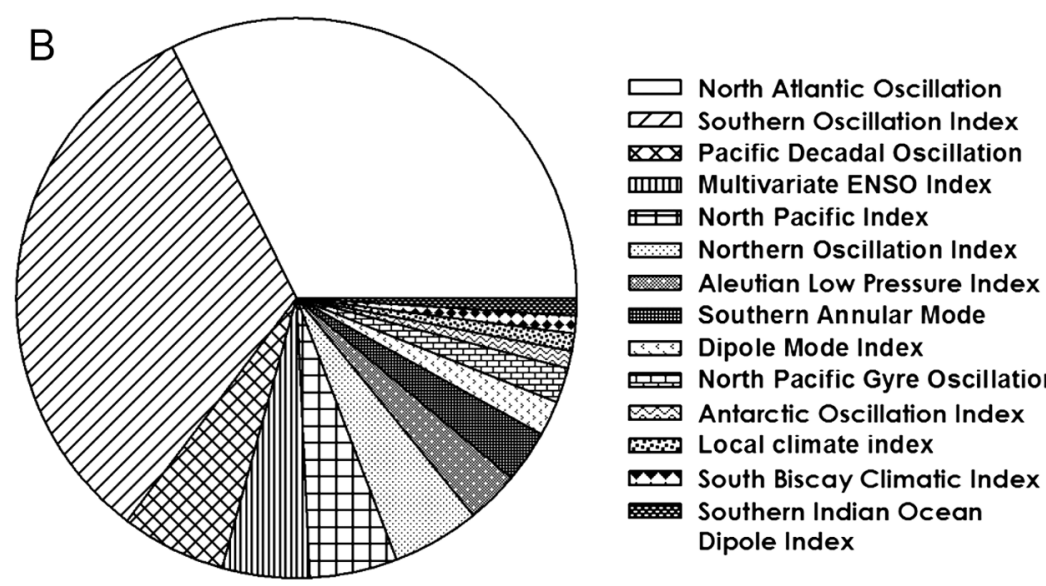

Fig. 2. (A) Seabird responses and (B) climatic indices studied in 108 publications on seabirds and climate change

understanding mechanisms of change in seabird populations and communities will be facilitated by matching variation in local to regional-scale marine climate with global climate models (GCMs). However, the fact that GCMs provide output on relatively large spatial scales whereas seabirds respond to environmental factors operating at local and regional scales remains a challenge. Moreover, for the oceans, GCMs demonstrate ubiquitous warming, whereas some regions of the oceans, notably eastern boundary current upwelling ecosystems are cooling (Burrows et al. 2011). Therefore, down-scaling and correcting the models to account for regional cooling trends are required before seabird data can be integrated with results from GCMs. Without such inputs from the climate modeling community, attribution of changes in seabird parameters to climate change will remain limited in geographic scope and may lead to biased and erroneous conclusions.

\section{Significance of effects by biome}

From our literature review, we categorized previous studies by Longhurst biome (tropical/sub-tropical, transitional, sub-polar/polar; Longhurst 2007)

\section{Climate parameters studied}

Based on our meta-analysis, the large-scale climate indices previously studied were dominated by the Southern Oscillation Index (SOI) and North Atlantic Oscillation (NAO); these 2 variables accounted for roughly $2 / 3$ of all seabird-climate records (Fig. 2B). In this TS, the SOI, NAO, Pacific Decadal Oscillation (PDO), and Arctic Oscillation (AO) were all studied in about equal proportions (Table 1); in addition, local and regional air and sea temperature, ice cover and other variables (especially winds and currents) were well-represented. Meta-analysis also revealed that no study to date has considered the effects of ocean acidification $\left(\mathrm{pCO}_{2}\right.$ or $\left.\mathrm{pH}\right)$ or de-oxygenation on seabird food resources, despite the fact that these physical variables have garnished significant attention, especially in the past decade (Doney et al. 2012). While basin-scale climate indices often provide strong correlations with seabird variables, and examined the significance of all climatic factors combined by biome with respect to their effects on seabird variables. Overall, about $31 \%$ of the seabirdclimate records obtained in tropical biomes were significant (defined as a statistical test with $\mathrm{p}<0.05$ ). This declined to about $20 \%$ being significant in the transitional biomes, and $17 \%$ significant in the subpolar/polar biome (Fig. 3A); these differences were significantly different (logistic regression, $\mathrm{p}<0.05$ ). As noted in 'Global coverage' above, previous studies in tropical/sub-tropical systems were relatively rare, but despite the limited sample size of seabirdclimate records in this biome, our analysis suggests that tropical seabird species and populations may be at least as sensitive to climate change as mid- or high-latitude ones. Further research is needed to ascertain whether this observation is robust. In this TS, only Surman et al. (2012) provide new information to enhance the number of tropical/sub-tropical studies worldwide. 

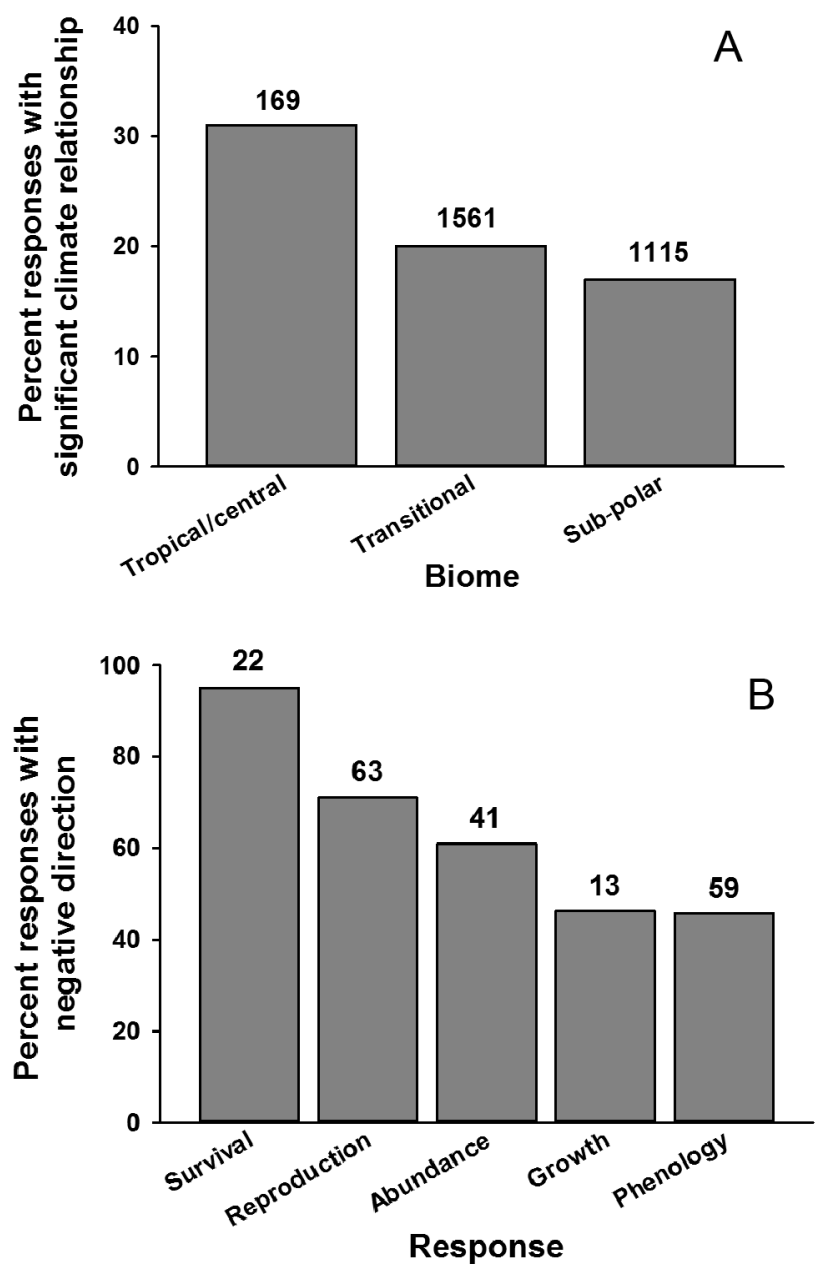

Fig. 3. (A) Percentage of statistically significant $(p<0.05)$ seabird responses to climatic factors by Longhurst biome (Longhurst 2007). (B) Percentage of seabird responses that had a negative relationship with sea surface temperature in the transitional biome by response type. Reproduction: reproductive success. Numbers above bars: sample size (n)

\section{Variation in temperature effects}

Within the transitional biome, there were sufficient data to assess the effects of sea surface temperature on a suite of different seabird parameters (Fig. 3B). Survival was almost always (>90\% of records) negatively related to increasing temperature, and about $70 \%$ of the time reproductive success was also negatively related. In contrast, relationships with temperature were equally positive and negative for relative abundance, growth and condition, and phenology. This variation suggests that general hypotheses concerning climate warming and its effects on marine life (e.g. earlier phenology, poorer reproduction, and pole-ward shifts in distribution; Doney et al. 2012) may not always be applicable to seabirds, or may be associated with multiple mechanisms operating simultaneously (e.g. immigration and shifts in range), with opposing signs in relation to temperature or other climatic factors. Instead, this variation highlights the need to consider regional and local mechanisms to elucidate both positive and negative relationships between climate and seabird parameters.

\section{DISPARATE MECHANISMS OF RESPONSE}

Since seabirds are heterotrophic, nektonic marine organisms, it is not surprising that most previous studies of climate variability effects on seabirds suggest indirect mechanisms, operating through variation in water column characteristics (Ainley \& Hyrenbach 2010) or food webs and prey availability (Barbraud et al. 2012, Dorresteijn et al. 2012, Thompson et al. 2012a). Direct effects, however, are possible, though these have been under-studied. For example, sea level rise may inundate low-lying breeding colonies, but most low-lying breeding sites are located in the tropics where seabird-climate studies are comparatively rare. Physiological stress due to overheating on colonies is also possible (Gaston et al. 2002, Oswald et al. 2008), but has not been adequately addressed to date, with most authors focusing on water instead of air temperature (but see Lynch et al. 2012, Smith \& Gaston 2012, Watanuki \& Ito 2012). Climate change-induced increases in wind fields could affect foraging success; in the case of procellarid seabirds which rely on wind for flight capacity, this change may improve foraging success with positive demographic consequences (Weimerskirch et al. 2012). In this TS, the direct negative impacts of wind are demonstrated by Hass et al. (2012), who alert us to the effect of hurricanes on the extinction risk of an endangered species (Table 2). Future studies on direct mechanisms of response in seabirds are warranted.

Indirect effects and food-related mechanisms of response, however, dominate the studies in this TS (Table 2), as they do in the literature. Briefly, the amount of energy available to seabirds in the environment plays a significant role in many, if not most, seabird-climate relationships. Underlying this concept is the assumption of bottom-up food web interactions, i.e. that climate variability and change affect primary productivity with amplified effects to mid(zooplankton and forage fish) and upper (seabird) trophic levels. In this TS, Burthe et al. (2012), Pro- 
Table 2. Major findings of articles in this Theme Section

\begin{tabular}{|c|c|c|}
\hline Authors & Scale & Primary mechanism(s) of response \\
\hline Burthe et al. & Regional & $\begin{array}{l}\text { Temporal mismatch in abundance between trophic levels limits bottom-up } \\
\text { energy transfer }\end{array}$ \\
\hline Lynch et al. & Local & $\begin{array}{l}\text { Change in timing can result in greater interspecific competition for nesting } \\
\text { space on colonies }\end{array}$ \\
\hline Surman et al. & Regional & $\begin{array}{l}\text { Changes in large-scale currents and eddy kinetic energy limit prey availabil- } \\
\text { ity to breeding birds }\end{array}$ \\
\hline Thompson et al. & Mesoscale & Ocean warming and lengthened growing season allow delay of migration \\
\hline Provencher et al. & Regional & $\begin{array}{l}\text { Loss of sea ice alters forage fish community due to reduction in primary } \\
\text { productivity }\end{array}$ \\
\hline Watanuki \& Ito & Local, regional & $\begin{array}{l}\text { (1) Arctic winds cause freezing of nesting habitat, restricting access } \\
\text { (2) Currents and advection alter forage fish community and prey availability }\end{array}$ \\
\hline Grémillet et al. & Regional & $\begin{array}{l}\text { Plasticity in foraging behavior buffers response to climate variability and prey } \\
\text { availability }\end{array}$ \\
\hline Dorresteijn et al. & Regional & $\begin{array}{l}\text { Ocean warming causes a change in diet and nutritional stress of planktivorous } \\
\text { seabirds }\end{array}$ \\
\hline Satterthwaite et al. & Basin & $\begin{array}{l}\text { Warming drives nutritional stress-induced mortality of piscivores to the } \\
\text { benefit of northern but not southern sites }\end{array}$ \\
\hline Smith \& Gaston & Regional & Lagged effects of climate variation affect different demographic attributes \\
\hline Hass et al. & Basin & High wind events cause habitat displacement and mortality \\
\hline Sidhu et al. & Regional & Increased spatial temperature gradients between water masses affect survival \\
\hline Sandvik et al. & Basin & $\begin{array}{l}\text { Life history trade-offs between survival and reproduction or recruitment } \\
\text { predict population response }\end{array}$ \\
\hline Barbraud et al. & Basin & Interaction of long-line fisheries bycatch and climate influences populations \\
\hline
\end{tabular}

vencher et al. (2012), Watanuki et al. (2012), Grémillet et al. (2012), and Dorresteijn et al. (2012) show how seabird food webs are changing in different regions. The changes in food webs, exemplified by changes in seabird diet, sometimes (Burthe et al. 2012) but not always (Dorresteijn et al. 2012, Grémillet et al. 2012, Provencher et al. 2012, Watanuki \& Ito 2012) reflect changes in diet quality; often the food web change is driven by species abundance or availability (Dorresteijn et al. 2012). In some cases, these changes affect breeding success or other demographic attributes. Comparison of seabirds operating on different trophic levels may be particularly relevant in this regard. For example, at the Pribilof Islands, Alaska, opposite responses are observed between sympatric planktivorous (Dorresteijn et al. 2012) and piscivorous (Satterthwaite et al. 2012) seabird species to the same changes in the physical environment.

\section{CONCLUSIONS}

Based on the literature and supported by this TS, it is clear that seabirds are responding to climate change on a global scale and can contribute to our understanding of climate change effects on marine ecosystems. Yet, our interpretations are limited because despite having some of the best (long-term and comprehensive) biological time series in the marine realm, seabird data sets are still of insufficient duration to separate natural inter-decadal variability from human-induced climate change effects (i.e. Sidhu et al. 2012). Therefore, one of our key recommendations is the need to maintain and possibly enhance existing long-term research and monitoring programs, even in times of financial limitations. These programs are necessary to develop the time series required to provide strong inference concerning seabirds and anthropogenic global warming.

A second key part of our roadmap for the future involves developing better mechanistic hypothesis and testing seabird-climate relationships in a predictive context. As noted in this TS, some mechanisms are apparently stronger than others. In particular, many climate-related effects appear to operate indirectly, with changes to seabird trophic ecology most often proposed as an explanatory mechanism (Table 2). Rarely, however, is concurrent information on prey abundance available to link climate, oceanographic conditions, food resources, and seabird responses. Moreover, for a global assessment of climatic effects on seabirds, we need to investigate and demonstrate such mechanisms across sites and eco- 
systems. While it is not practical to monitor food resources for many colonies or ecosystems, new physiological tools which directly relate nutritional stress to population processes (Kitaysky et al. 2007, 2010) can be applied on relatively large geographical scales at reasonable expense (Satterthwaite et al. 2012, Dorrensteijn et al. 2012); measurements of the stress hormone corticosterone might be particularly useful in this regard (Barbraud et al. 2012). Also needed, however, is better information about the demography, structure (genetics), and connectivity (dispersal statistics) of seabird populations. As shown by Sandvik et al. (2012), to understand the 'fitness landscape', fecundity and survival need to be measured simultaneously with concurrent measurements of changes in the physical environment. Seabirds may be buffered sufficiently to overcome nutritional deficits and reproduce successfully (Grémillet et al. 2012), but this could come at the cost of their survival.

Third, given the need for a global assessment and greater understanding of mechanisms involving primary productivity and food webs, both physical oceanography and ecosystem science will be a backbone for seabird climate change ecology. We see integration of numerical oceanographic (e.g. Regional Ocean Modeling System [ROMS]), ecosystem (e.g. Nutrient-Phytoplankton-Zooplankton [NPZ] models) and individual-based population dynamics models of seabirds as a fruitful approach. For example, ROMS models could be forced by output from the next generation of GCMs to provide key information about the likelihood of change in pelagic, and perhaps coastal, habitats. NPZ models coupled with ROMS could provide information on key changes in seabird food webs and prey abundance. Finally, population dynamics models could integrate changes in habitat characteristics and food resources in the predictive demographic framework advocated above (this section). In this manner, mechanisms of change (pathways of response) could be articulated and tested mathematically, and subsequently compared and verified using empirical data (Jenouvrier et al. 2009, Wolf et al. 2010). The road map to the future, thus, includes more 'end-to-end' modeling and longterm empirical studies with an emphasis on interdisciplinary research. Only through such an integrative approach will accurate predictions of change in seabird populations be possible, thereby facilitating seabird conservation in a changing world.

Acknowledgements. We thank the WSC International Steering Committee, PSG, Packard Foundation, Marisla Foundation and the world seabird community for making the seabirds and climate change symposium and this Theme Section possible. PSG and the WSC are thanked for Open Access funding. In addition to the authors, editorial contributions were provided by Drs. Hans Heinrich Janssen and Rory P. Wilson. We sincerely appreciate the thoughtful comments of dozens of independent reviewers.

\section{LITERATURE CITED}

Ainley DG, Hyrenbach KD (2010) Top-down and bottom-up factors affecting seabird population trends in the California Current system (1985-2006). Prog Oceanogr 84: 242-254

> Barbraud C, Weimerskirch H (2001) Emperor penguins and climate change. Nature 411:183-186

Barbraud C, Rolland V, Jenouvrier S, Nevoux M, Delord K, Weimerskirch H (2012) Effects of climate change and fisheries bycatch on Southern Ocean seabirds: a review. Mar Ecol Prog Ser 454:285-307

> Beaugrand G, Reid PC, Ibanez F, Lindley JA, Edwards M (2002) Reorganization of North Atlantic marine copepod biodiversity and climate. Science 296:1692-1694

Belkin IM (2009) Rapid warming of large marine ecosystems. Prog Oceanogr 81:207-213

Brown CJ, Schoeman DS, Sydeman WJ, Brander K and others (2011) Quantitative approaches in climate change ecology. Glob Change Biol 17:3697-3713

Burrows MT, Schoeman DS, Buckley LB, Moore P and others (2011) The pace of shifting climate in marine and terrestrial ecosystems. Science 334:652-655

Burthe S, Daunt F, Butler A, Elston DA and others (2012) Phenological trends and trophic mismatch across multiple levels of a North Sea pelagic food web. Mar Ecol Prog Ser 454:119-133

Cairns DK (1987) Seabirds as indicators of marine food supplies. Biol Oceanogr 5:261-271

> Croxall JP, Butchart SHM, Lascelles B, Stattersfield AJ, Sullivan B, Symes A, Taylor P (2012) Seabird conservation status, threats and priority actions: a global assessment. Bird Conserv Int 22:1-34

Cury PM, Boyd IL, Bonhommeau S, Anker-Nilssen T and others (2011) Global seabird response to forage fish depletion-one-third for the birds. Science 334: 1703-1706

> Doney SC, Ruckelshaus M, Duffy JE, Barry JP and others (2012) Climate change impacts on marine ecosystems. Annu Rev Mar Sci 4:11-37

> Dorresteijn I, Kitaysky AS, Barger C, Benowitz-Fredericks ZM, Byrd GV, Shultz M, Young R (2012) Climate affects food availability to planktivorous least auklets Aethia pusilla through physical processes in the southeastern Bering Sea. Mar Ecol Prog Ser 454:207-220

> Durant JM, Hjermann DO, Frederiksen M, Charrassin JB and others (2009) Pros and cons of using seabirds as ecological indicators. Clim Res 39:115-129

> Furness RW, Tasker ML (2000) Seabird-fishery interactions: quantifying the sensitivity of seabirds to reductions in sandeel abundance, and identification of key areas for sensitive seabirds in the North Sea. Mar Ecol Prog Ser 202:253-264

> Gaston AJ, Hipfner JM, Campbell D (2002) Heat and mosquitoes cause breeding failures and adult mortality in an Arctic-nesting seabird. Ibis 144:185-191 
Grémillet D, Welcker J, Karnovsky NJ, Walkusz W and others (2012) Little auks buffer the impact of current Arctic climate change. Mar Ecol Prog Ser 454:197-206

Harley CDG, Hughes AR, Hultgren KM, Miner BG and others (2006) The impacts of climate change in coastal marine systems. Ecol Lett 9:228-241

Hass T, Hyman J, Semmens BX (2012) Climate change, heightened hurricane activity, and extinction risk for an endangered tropical seabird, the black-capped petrel Pterodroma hasitata. Mar Ecol Prog Ser 454:251-261

Hegerl GC, Zwiers FW, Braconnot P, Gillett NP and others (2007) Understanding and attributing climate change. In: Solomon S, Qin D, Manning M, Chen Z and others (eds) Climate change 2007: the physical science basis. Contribution of Working Group I to the Fourth Assessment Report of the Intergovernmental Panel on Climate Change. Cambridge University Press, Cambridge p 663-745

$>$ Hoegh-Guldberg O, Bruno JF (2010) The impact of climate change on the world's marine ecosystems. Science 328: 1523-1528

IUCN (2011) The IUCN Red List of Threatened Species. V. 2011.2. www.iucnredlist.org. Accessed on 1 May 2012

> Jenouvrier S, Caswell H, Barbraud C, Holland M, Stroeve J, Weimerskirch H (2009) Demographic models and IPCC climate projections predict the decline of an emperor penguin population. Proc Natl Acad Sci USA 106: 1844-1847

Kitaysky A, Golubova EG (2000) Climate change causes contrasting trends in reproductive performance of planktivorous and piscivorous alcids. J Anim Ecol 69: 248-262

Kitaysky AS, Piatt JF, Wingfield JC (2007) Stress hormones link food availability and population processes in seabirds. Mar Ecol Prog Ser 352:245-258

Kitaysky AS, Piatt JF, Hatch SA, Kitaiskaia EV, BenowitzFredericks ZM, Shultz MT, Wingfield JC (2010) Food availability and population processes: severity of nutritional stress during reproduction predicts survival of long-lived seabirds. Funct Ecol 24:625-637

> Levitus S, Antonov JI, Boyer TP, Locarnini RA, Garcia HE, Mishonov AV (2009) Global ocean heat content 19552008 in light of recently revealed instrumentation problems. Geophys Res Lett 36:L07608, doi:10.1029/2008GL 037155

> Lewison R, Oro D, Godley B, Underhill L and others (2012) Research priorities for seabirds: improving conservation and management in the 21st century. Endang Species Res 17:93-121

Longhurst A (2007) Ecological geography of the sea. 2nd edn. Academic Press, Burlington, MA

- Lynch HJ, Fagan WF, Naveen R, Trivelpiece SG, Trivelpiece WZ (2012) Differential advancement of breeding phenology in response to climate may alter staggered breeding among sympatric pygoscelid penguins. Mar Ecol Prog Ser 454:135-145

MEPS (2007) Theme Section: Seabirds as indicators of marine ecosystems. Mar Ecol Prog Ser 352:199-309

MEPS (2009) Theme Section: Marine ecosystems, climate and phenology: impacts on top predators. Mar Ecol Prog Ser 393:184-299

Oswald SA, Bearhop S, Furness RW, Huntley B, Hamer KC (2008) Heat stress in a high-latitude seabird: effects of temperature and food supply on bathing and nest atten- dance of great skuas Catharacta skua. J Avian Biol 39: 163-169

> Parmesan C (2007) Influences of species, latitudes and methodologies on estimates of phenological response to global warming. Glob Change Biol 13:1860-1872

Parmesan C, Yohe G (2003) A globally coherent fingerprint of climate change impacts across natural systems. Nature 421:37-42

Perry AL, Low PJ, Ellis JR, Reynolds JD (2005) Climate change and distribution shifts in marine fishes. Science 308:1912-1915

Provencher JF, Gaston AJ, O'Hara PD, Gilchrist HG (2012) Seabird diet indicates changing Arctic marine communities in eastern Canada. Mar Ecol Prog Ser 454:171-182

Richardson AJ (2008) In hot water: zooplankton and climate change. ICES J Mar Sci 65:279-295

> Richardson AJ, Poloczanska ES (2008) Ocean science under-resourced, under threat. Science 320:1294-1295

Rosenzweig C, Karoly D, Vicarelli M, Neofotis P and others (2008) Attributing physical and biological impacts to anthropogenic climate change. Nature 453:353-357

Sandvik H, Erikstad KE, Sæther BE (2012) Climate affects seabird population dynamics both via reproduction and adult survival. Mar Ecol Prog Ser 454:273-284

Satterthwaite WH, Kitaysky AS, Mangel M (2012) Linking climate variability, productivity and stress to demography in a long-lived seabird. Mar Ecol Prog Ser 454: 221-235

> Sidhu LA, Dann P, Chambers L, Catchpole EA (2012) Seasonal ocean temperature and the survival of first-year little penguins Eudyptula minor in south-eastern Australia. Mar Ecol Prog Ser 454:263-272

Smith PA, Gaston AJ (2012) Environmental variation and the demography and diet of thick-billed murres. Mar Ecol Prog Ser 454:237-249

Solomon S, Qin D, Manning M, Chen Z and others (2007) Climate change 2007: the physical science basis. Contribution of Working Group I to the Fourth Assessment Report of the Intergovernmental Panel on Climate Change. Cambridge University Press, Cambridge

Stenseth NC, Mysterud A, Ottersen G, Hurrell J, Chan K, Lima M (2002) Ecological effects of climate fluctuations. Science 297:1292-1296

> Surman CA, Nicholson LW, Santora JA (2012) Effects of climate variability on breeding phenology and performance of tropical seabirds in the eastern Indian Ocean. Mar Ecol Prog Ser 454:147-157

- Thompson SA, Sydeman WJ, Santora JA, Black BA and others (2012a) Linking predators to seasonality of upwelling: using food web indicators and path analysis to infer trophic connections. Prog Oceanogr (in press), doi: 10.1016/j.pocean.2012.02.001

Thompson SA, Sydeman WJ, Santora JA, Morgan KH, Crawford W, Burrows MT (2012b) Phenology of pelagic seabird abundance relative to marine climate change in the Alaska Gyre. Mar Ecol Prog Ser 454:159-170

Ware DM, Thomson RE (2005) Bottom-up ecosystem trophic dynamics determine fish production in the Northeast Pacific. Science 308:1280-1284

- Watanuki Y, Ito M (2012) Climatic effects on breeding seabirds of the northern Japan Sea. Mar Ecol Prog Ser 454:183-196

Weimerskirch H, Louzao M, de Grissac S, Delord K (2012) 
Changes in wind pattern alter albatross distribution and life-history traits. Science 335:211-214

- Wolf SG, Snyder MA, Sydeman WJ, Doak DF, Croll DA (2010) Predicting population consequences of ocean climate change for an ecosystem sentinel, the seabird Cassin's auklet. Glob Change Biol 16:1923-1935
Young L, Suryan RM, Duffy D, Sydeman WJ (2012) Climate change and seabirds of the California Current and Pacific Island ecosystems: observed and potential impacts and management implications. Final report to the US Fish and Wildlife Service, Region 1. Pacific Rim Conservation, Honolulu, HI 